\title{
Embalagem de tecido de algodão: análise do uso em hospitais de médio e grande porte
}

\author{
The use of cotton tissue packages in medium- and large-sized hospitals: an analysis \\ Embalaje de tejido de algodón: análisis del uso en hospitales de medio y gran porte \\ Lucimara Rodrigues de Freitas ${ }^{1}$, Anaclara Ferreira Veiga Tipple², Dirce Pires Felipe ${ }^{3}$, \\ Neuraci dos Santos Ramos Rodrigues ${ }^{4}$, Dulcelene de Souza Melo ${ }^{5}$
}

\section{RESUMO}

O presente estudo teve como objetivo geral analisar o uso do tecido de algodão como embalagem de produtos para saúde processados em hospitais de médio e grande porte. Os dados foram coletados por análise de amostras novas de tecido e aplicação de questionário aos enfermeiros responsáveis pelo Centro de Material e Esterilização. Participaram 16 hospitais, sendo que em oito deles (50\%) o enfermeiro da unidade era o responsável pela aquisição do tecido de algodão, porém, quatro (25\%) não descreveram os critérios adotados. Os campos eram confeccionados de modo simples em seis hospitais $(37,6 \%)$ e cinco $(31,2 \%)$ utilizavam um campo simples e um duplo para a montagem dos pacotes. Um hospital relatou controle do reuso dos campos e na maioria o tecido tinha de 40 a 56 fios $/ \mathrm{cm}^{2}$. Os critérios mínimos para as embalagens de tecido de algodão foram identificados nas amostras analisadas, entretanto, o monitoramento da vida útil da embalagem era negligenciado na maioria dos hospitais.

Descritores: Embalagem de Produtos; Fibra de Algodão; Esterilização.

\section{ABSTRACT}

The general objective of the present study was to analyze the use of cotton tissue packaging for health products processed in medium- and large-sized hospitals. Data collection was performed by analyzing new tissue samples and applying a questionnaire with nurses in charge of the Materials and Sterilization Center. Sixteen hospitals participated, eight of which (50\%) assigned the unit nurse as the professional in charge for purchasing the cotton tissue, while four $(25 \%)$ did not describe the criteria they followed. In six hospitals, layers were assembled following a simple fashion (37.6\%) while five hospitals (31.2\%) used one simple and one double layer to assemble the packages. One hospital reported controlling the reutilization of the layers, and the tissue usually had 40 to 56 threads $/ \mathrm{cm}^{2}$. The minimum criteria for the cotton tissue packages were identified in the analyzed samples; however, the monitoring of the package's life cycle was neglected in most hospitals.

Descriptors: Product Packaging; Cotton Fiber; Sterilization.

\section{RESUMEN}

Estudio que objetivó analizar el uso del tejido de algodón como embalaje de productos sanitarios procesados en hospitales de mediano y gran porte. Datos recolectados mediante análisis de muestras nuevas de tejido y aplicación de cuestionario a enfermeros responsables por el Centro de Material y Esterilización. Participaron 16 hospitales; en ocho (50\%), el enfermero de la unidad era responsable por la adquisición del tejido; sin embargo, cuatro (25\%) no describieron los criterios adoptados. Los paño eran confeccionados simples en seis hospitales $(37,6 \%)$, y cinco $(31,2 \%)$ utilizaban un paño simple y uno doble para embalar los paquetes. Un hospital relató controlar la reutilización de los paños. En la mayoría, el tejido era de 40 a 56 hilos/cm². Los criterios mínimos para los embalajes de tejido de algodón fueron identificados en las muestras analizadas, mientras que el monitoreo de la vida útil del embalaje se descuidaba en la mayoría de los hospitales.

Descriptores: Embalaje de Productos; Fibra de Algodón; Esterilización.

\footnotetext{
${ }^{1}$ Enfermeira. Discente do Programa de Pós-Graduação em Enfermagem da Faculdade de Enfermagem (FEN) da Universidade Federal de Goiás (UFG), nível Mestrado. Enfermeira do Centro Cirúrgico do Hospital das Clínicas da UFG. Goiânia, GO, Brasil. E-mail: lurodriguesfreitas@yahoo.com.br.

${ }^{2}$ Enfermeira, Doutora em Enfermagem. Professora Associada da FEN/UFG. Goiânia, GO, Brasil. E-mail: anaclara@fen.ufg.br.

${ }^{3}$ Enfermeira. Enfermeira do Centro de Material e Esterilização e Centro Cirúrgico do Hospital de Doenças Tropicais. Goiânia, GO, Brasil. E-mail: dircefpires@gmail.com.

${ }^{4}$ Enfermeira. Goiânia, GO, Brasil. E-mail: neuraci.rodriques@hotmail.com.

${ }^{5}$ Enfermeira, Mestre em Enfermagem. Discente do Programa de Pós-Graduação em Enfermagem da FEN/UFG. Professora Assistente da FEN/UFG. Goiânia, GO, Brasil. E-mail: dsmelo11@yahoo.com.br.
} 


\section{INTRODUÇÃO}

O processamento seguro de produtos para saúde é uma das principais medidas de prevenção e controle de infecções associadas aos cuidados em saúde, reduzindo o risco de iatrogenias ${ }^{(1)}$. Envolve etapas sequenciais, com características próprias em cada uma: pré-limpeza, recepção, limpeza, secagem, avaliação da integridade e da funcionalidade, preparo, desinfecção ou esterilização, armazenamento e distribuição para as unidades consumidoras( ${ }^{(2)}$.

O calor úmido, vapor saturado sob pressão, é um processo de esterilização amplamente utilizado em produtos para saúde termorresistentes, em grande parte das instituições de saúde no Brasil e no mundo. Tem como vantagens: rápido aquecimento, destruição rápida dos esporos microbianos, fácil controle de qualidade, ausência de resíduos tóxicos e economia ${ }^{(3-4)}$.

Um dos pontos que definem a qualidade do processamento é a seleção da embalagem compativel ao método de esterilização. Diversas embalagens são recomendadas para a esterilização a vapor saturado sob pressão, dentre elas papel grau cirúrgico, não tecido SMS, contêineres rígidos, tecido de algodão e outras ${ }^{(4-5)}$. Devem ser dotadas de várias propriedades, dentre as quais a de permeabilidade ao ar e ao agente esterilizante, secagem do conteúdo e barreira microbiana eficaz. Essas, além de propiciarem a esterilização, promovem a proteção dos produtos de condições adversas durante $\mathrm{o}$ transporte e armazenamento, e possibilita a abertura asséptica ${ }^{(4,6)}$.

O tecido de algodão é uma das embalagens mais antigas e ainda hoje é amplamente utilizadopara a esterilização em vapor saturado sob pressão. A NBR n. 12546/91, o define como uma estrutura de entrelaçamento de um conjunto de fios dispostos no sentido longitudinal (urdume $=\mathrm{U}$ ) com outro conjunto de fios dispostos no sentido transversal (trama $=\mathrm{T}$ ), formando um ângulo de $90^{\circ}(7)$. Entende-se tecido de algodão cru aquele não submetido a processos químicos, como clareamentos ou tinturas.

No século XIX a musselina $100 \%$ algodão foi o primeiro material têxtil para embalagem de produtos para saúde, mas sua alta porosidade facilitava a contaminação. Iniciou na década de 50 o uso de tecido $100 \%$ de algodão, resistente a 30 ciclos de lavagem e esterilização, passando na década de 70 para tecido misto (50\% algodão e $50 \%$ poliéster), tratado quimicamente para aumentara resistência à umidade ${ }^{(5)}$.

Atualmente, as especificações do tecido de algodão como embalagem de produtos para saúde são definidas pela NBR n. 14027 (para campos simples) e NBR n. 14028 (para campos duplos). Ambas estabelecem o tecido $100 \%$ de algodão, com padrão sarja T1(2x1), com 210 $\mathrm{g} / \mathrm{m}^{2}$ de gramatura e textura de 40 a 56 fios por $\mathrm{cm}^{2}$ de tecido ${ }^{(8-9)}$.

A Association of Operating Room Nurses-AORN, adota, além dos critérios de escolha do tecido, indicações para o usocomo: lavar o tecido antes do primeiro uso, para retirar o amido e após cada uso para remover sujidade e restaurar a umidade; realizar testes de permeabilidade com água; estabelecer o número máximo de processamentos; não deve sofrer processo de calandragem ou apresentar cerzimentos e remendos; deve ser mantido em temperaturade $18^{\circ} \mathrm{C}$ a $22^{\circ} \mathrm{C}$ e umidade relativa de $35 \%$ a $70 \%{ }^{(10)}$.

Dentre as vantagens de uso do tecido de algodão cru ressaltam-se a economia (muitas vezes desconsiderando os custos indiretos), a propriedade de memória e resistência da embalagem, que se aproximam de níveis ideais. As desvantagens são a facilidade de contaminação da embalagem, o baixo nível de barreira a microrganismos (em torno de 30\%) e a dificuldade de controlar o número de processamentos ${ }^{(4-5)}$.

A efetividade de tecidos duplos $100 \%$ de algodão, sarja tipo T1 (em que há dois fios no urdume para cada fio entrelaçado na trama), foi avaliada como barreira microbiana, seguindo a metodologia alemã preconizada pela norma DNI n. 58.953/87. Concluíram que a embalagem é efetiva em até 65 vezes de reprocessamento, incluindo lavagem e autoclavação. Tais resultados demonstraram a segurança e eficácia dessa embalagem, no entanto, indicam a necessidade de controle no seu reuso, atentando para sua finitude e quebra da capacidade de manutenção de barreira microbiana ${ }^{(11)}$.

Estudo semelhante avaliou a eficácia da barreira microbiana do campo cirúrgico simples de algodão destinado a isolar a ferida operatória durante a cirurgia, conforme padronização da NBR n. 14027/97, e concluiu que houve quebra da barreira microbiana a partir do sexto processamento, bem como progressiva redução do peso dos campos e consequente desprendimento de fibras, comparando da primeira à sexta lavagem ${ }^{(12)}$. 
Grande parte dos serviços de saúde utiliza o tecido de algodão cru como embalagem de produtos para saúde, estimulados principalmente pelo seu baixo custo e possibilidade de reuso. Entretanto, há um desconhecimento se as recomendações e critérios de seleção e uso estão sendo implementados, de formaa promover esterilização e manutenção da esterilidade dos produtos para saúde.

Com ênfase no desenvolvimento sustentável e gerenciamento de resíduos dos serviços de saúde, interessa a utilização mínima de embalagens descartáveis, reduzindo a geração de detritos sólidos e consequente degradação ambiental. O tecido de algodão é uma alternativa viável e segura, quando usado dentro das indicações.

Este estudo teve como objetivo geral analisar o uso do tecido de algodão como embalagem de produtos para saúde processados em hospitais de médio e grande porte. Os objetivos específicos foram: identificar hospitais de médio e grande porte que utilizam o tecido de algodão como embalagem de produtos para saúde; identificar o responsável pela aquisição do tecido e os critérios adotados para compra; descrever o modo de confecção e os critérios de seleção dos campos para o empacotamento; descrever as formas de controle para reuso e analisar amostras novas de tecido utilizadas como invólucro, avaliando o padrão do tecido, $n^{\circ}$ de fios na trama (fios no sentido transversal), $n^{\circ}$ de fios no urdume (fios no sentido longitudinal), $\mathrm{n}^{\circ}$ de fios por $\mathrm{cm}^{2}$ e gramatura.

\section{MATERIAIS E MÉTODOS}

Estudo transversal, descritivo com abordagem quantitativa. O Projeto foi aprovado pelo Comitê de Ética em Pesquisa do Hospital de Urgências de GoiâniaHUGO, sob o protocolo $n^{\circ} 64 / 08$ epor outros cinco hospitais que exigiram análise de seus Comitês.

Os critérios de inclusão quanto aos hospitais foram: ser público, particular ou filantrópico, de médio e grande porte do município de Goiânia-GO e utilizar o método de esterilização de vapor saturado sob pressão. Quanto aos enfermeiros, ser responsável pelo Centro de Material e Esterilização (CME) e/ou Centro Cirúrgico, considerando queteria, provavelmente, um maior vínculo com a unidade de CME e suas especificidades.

A Associação dos Hospitais do Estado de Goiás reportou no ano de 2008, 26 hospitaisde médio e grande porte. Todos foram contatados, sete recusaram participar, justificando não terem interesse no tema oupermitirem pesquisas somente do corpo clínico interno e três não tinham enfermeiros exclusivos como responsável pelo CME e/ou Centro Cirúrgico. A investigação foi realizada em $16(61,5 \%)$ hospitais.

Os dados foram coletados de setembro de 2008 a fevereiro de 2009 e obtidos pela aplicação de um questionário semiestruturado e análise de amostras de tecido. O questionário continha questões fechadas e abertas e foi avaliado quanto à forma e conteúdo por profissionais com experiência na área, visando seu aperfeiçoamento.

O preenchimento foi individual, no local de trabalho, por um(a) enfermeiro(a) do CME e/ou Centro cirúrgico de cada instituição. O dia e o horário para a coleta foi agendado por telefone de acordo com a disponibilidade do entrevistado, após sua aquiescência em participar e assinatura do Termo de Consentimento Livre e Esclarecido.

Todas as instituições forneceram um campo pequeno ou fragmento de pelo menos $10 \mathrm{~cm}^{2}$ de tecido novo e cada amostra foi numerada de um a 16. Posteriormente foi feita a análise do tecido avaliando os seguintes critérios: padrão (ligamento tipo tela ou sarja); $n^{\circ}$ de fios na trama (fios no sentido transversal), $n^{\circ}$ de fios no urdume (fios no sentido longitudinal), $n^{\circ}$ de fios por $\mathrm{cm}^{2}$ e gramatura.

A análise das amostras de tecido foi realizada pelos próprios pesquisadores na seção de costura do Hospital das Clínicas da Universidade Federal de Goiás, com o consentimento do enfermeiro gerente, que disponibilizou os instrumentos acessórios ali usados. Para a contagem do número de fios na trama $(T)$ e urdume (U) do tecido, foi utilizado agulha e lupa FOLDABLE MAGNIFIER ${ }^{\circledR}$ que delimita a análise em $1 \mathrm{~cm}^{2}$. Como contra prova foram desfiados os fios da trama e urdume de $1 \mathrm{~cm}^{2}$ de cada amostra.

Na análise da gramatura as amostras de tecido foram pesadas em balança digital de precisão, da marca $K E R N^{\circledR}$. Por indisponibilidade de amostras de $1 \mathrm{~m}^{2}$, foi feita a proporcionalidade matemática dopeso encontrado em $10 \mathrm{~cm}^{2}$ de tecido, comprovada ao comparar os valores do peso de um campo de tecido de $1 \mathrm{~m}^{2}$ com a fórmula para cálculo de gramatura: $M^{2}=$ (Peso/ Metro) / largura. 
Os dados foram processados pelo programa Microsoft Excel versão 2007 e analisados com auxílio da estatística descritiva, pela medida de frequência simples. Os resultados foram dispostos em tabelas.

\section{RESULTADOS}

Os 16 hospitais de médio e grande porte do município de Goiânia-GO, participantes desse estudo, utilizavam o tecido de algodão como embalagem para produtos para saúde processados e suas características estão apresentadas na Tabela 1.

Tabela 1: Distribuição de hospitais de médio e grande porte do município de Goiânia-GO. (N=16), segundo razão social, porte e tipo de CME. Goiânia, GO, 2009.

\begin{tabular}{|c|c|c|}
\hline Caracterização das instituições & $\mathbf{n}$ & $\%$ \\
\hline \multicolumn{3}{|l|}{ Razão social } \\
\hline Privado & 10 & 62,5 \\
\hline Público & 04 & 25,0 \\
\hline Filantrópico & 02 & 12,5 \\
\hline \multicolumn{3}{|l|}{ Porte } \\
\hline Médio & 09 & 56,2 \\
\hline Grande & 07 & 43,8 \\
\hline \multicolumn{3}{|l|}{ Tipo de CME } \\
\hline Centralizado & 10 & 62,5 \\
\hline Semi centralizado & 06 & 37,5 \\
\hline Descentralizado & 00 & 0,0 \\
\hline
\end{tabular}

Em menos da metade $(43,8 \%)$ dos hospitais o enfermeiro supervisor trabalhava de forma exclusiva no CME. Em oito ele possuía atribuições e responsabilidades técnicas em outros setorescomo Centro Cirúrgico (37,5\%) e Serviço de Controle de Infecção Hospitalar $(18,7 \%)$.

Quanto aos invólucros utilizados para a esterilização no vapor saturado sob pressão, além do tecido de algodão, 13 hospitais (81,3\%) citaram o uso de outras embalagens, tais como, papel crepado (76,9\%), papel grau cirúrgico $(61,5 \%)$ e papel Kraft $(7,7 \%)$.

A constituição do tecidoem uso no hospital, para embalar produtos para saúde, foi definida por todos os enfermeiros como $100 \%$ de algodão, assim como acomposição das 16 amostras de $10 \mathrm{~cm}^{2}$ de tecido novo, contudo esta variável não foi experimentalmente certificada. Treze enfermeiros (81,3\%) não souberam responder as especificações do tecido: número de fios por $\mathrm{cm}^{2}$, padrão e gramatura.

Em três hospitais públicos $(18,8 \%)$ a compra dos tecidos era definida no nível administrativo, estadual ou municipal. Em cinco (31,2\%) o setor de compras era responsável exclusivo pela aquisição e em oito $(50,0 \%)$ os enfermeiros do CME e/ou Centro Cirúrgico participavam diretamente da definição da compra dos tecidos para invólucro. A Tabela 2 apresenta os critérios observados para compra do tecido.

Tabela 2: Distribuição dos hospitais de médio e grande porte do município de Goiânia-GO (N=16) segundo os critérios observados para compra do tecido de algodão usado como embalagem de produtos para saúde processáveis. Goiânia, GO, 2009.

\begin{tabular}{ccc}
\hline Critérios & $\mathbf{N}$ & $\mathbf{\%}$ \\
\hline Gramatura, $\mathrm{n}^{\circ}$ fios por $\mathrm{cm}^{2}$, cor e preço & 03 & 18,7 \\
Gramatura, $\mathrm{n}^{\circ}$ fios por $\mathrm{cm}^{2}$ e cor & 02 & 12,5 \\
Preço e cor & 02 & 12,5 \\
Gramatura, no de fios e preço & 01 & 6,3 \\
Gramatura & 01 & 6,3 \\
Preço & 01 & 6,3 \\
No de fios por cm $^{2}$ & 01 & 6,3 \\
Outros & 01 & 6,3 \\
Não souberam responder & 04 & 25,0 \\
\hline TOTAL & $\mathbf{1 6}$ & $\mathbf{1 0 0 , 0}$
\end{tabular}


Apenas três enfermeiros (18,7\%) citaram a associação entre os itens gramatura, número de fios por $\mathrm{cm}^{2}$, cor e preço do tecido, quatro $(25,0 \%)$ não souberam responder os critérios adotados para comprado tecido de algodão.

Questionados quanto à forma de análise e conferência da gramatura e $n^{\circ}$ de fios por $\mathrm{cm}^{2}$ de tecido, quatro $(25,0 \%)$ enfermeiros responderam não existir esse tipo de avaliaçãoe sete $(43,8 \%)$ não souberam informar como a conferência acontecia. Dois hospitais $(12,5 \%)$ adotavam forma sistemática de análise das amostras de tecido antes da compra, com uso de instrumentos acessórios como lupa e balança. Em três $(18,7 \%)$, eram conferidas apenas as especificações técnicas do fabricante.

Em seis hospitais $(37,6 \%)$ a confecção dos campos de algodão era de forma simples, em cinco $(31,2 \%)$ duplos e os demais utilizavam os dois tipos. O preparo dos pacotes, no momento de embalar os produtos para saúde, ocorria de diferentes formas, sendo a maior frequência, a utilização de um campo simples e um duplo, como mostra a Tabela 3.

Tabela 3: Distribuição dos hospitais de médio e grande porte do município de Goiânia- GO, segundo os campos de tecido usados para embalar os produtos para saúde processáveis, no momento do preparo dos pacotes. Goiânia, GO, 2009.

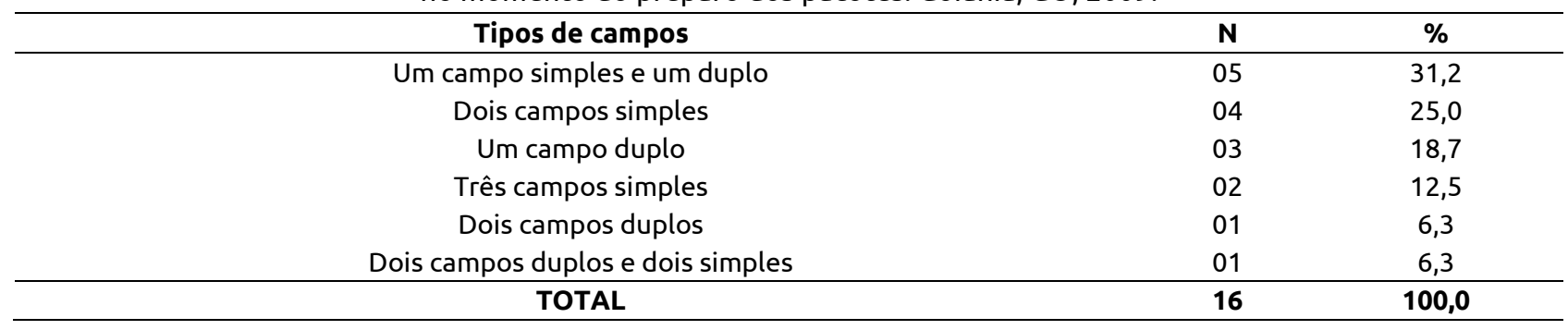

Todos os hospitais lavavam o tecido de algodão antes do primeiro uso eda sua reutilização. Em 15 $(93,7 \%)$ os campos eram lavados logo após a sua confecção e em um (6,3\%) antes e após. O número de lavagens era de uma $(43,8 \%)$ a duas vezes $(25,0 \%)$ e cinco enfermeiros $(31,2 \%)$ não souberam responder a esta questão.

Dez enfermeiros $(62,5 \%)$ citaram a associação de integridade e limpeza como critérios de seleção dos campos para a preparação dos pacotes, quatro $(25,0 \%)$ citaram somente a integridade e dois (12,5\%) a limpeza.

Quanto ao controle do número de vezes que a embalagem de tecido de algodãoera reutilizada, em 14 hospitais $(87,5 \%)$ não era feito qualquer tipo de monitoramento da sua vida útil. Em um havia controle sistemático dereuso dos campos de tecido, com substituição do enxoval a cada seis meses, período que correspondia a aproximadamente 120 processamentos. No outro o enfermeiro referiu que usava o invólucro "até que a integridade do tecido ofereça aproveitamento" e que era descartado "quando o campo não oferece boas condições de esterilização".

As descrições das características das amostras de tecido novo fornecidos pelos hospitais estão na Tabela 4. 
Tabela 4: Caracterização das amostras de tecido novo, usados como embalagens em hospitais de médio e grande porte do município de Goiânia (N=16). Goiânia, GO, 2009.

\begin{tabular}{|c|c|c|}
\hline Caracterização das amostras de tecido & $\mathbf{n}$ & $\%$ \\
\hline \multicolumn{3}{|l|}{ Constituição } \\
\hline Tecido de algodão cru & 07 & 43,8 \\
\hline Tecido de algodão tinto & 09 & 56,2 \\
\hline \multicolumn{3}{|l|}{ Padrão do tecido } \\
\hline Sarja T1 (2x1) & 05 & 31,3 \\
\hline Sarja T2 $(3 \times 1)$ & 11 & 68,7 \\
\hline \multicolumn{3}{|l|}{$\mathrm{N}^{\circ}$ de fios na Trama $(\mathrm{T})$} \\
\hline 17 fios & 02 & 12,5 \\
\hline 18 fios & 08 & 50,0 \\
\hline 19 fios & 01 & 6,3 \\
\hline 20 fios & 05 & 31,2 \\
\hline \multicolumn{3}{|l|}{$N^{\circ}$ de fios no Urdume (U) } \\
\hline Abaixo de 40 fios & 14 & 87,5 \\
\hline Igual a 40 fios & 01 & 6,3 \\
\hline Acima de 40 fios & 01 & 6,3 \\
\hline \multicolumn{3}{|l|}{$\mathrm{N}^{\circ}$ de fios em $1 \mathrm{~cm}^{2}$} \\
\hline Entre 40 e 56 fios & 14 & 87,5 \\
\hline Acima de 56 fios & 02 & 12,5 \\
\hline \multicolumn{3}{|l|}{ Gramatura } \\
\hline $210 \mathrm{~g} / \mathrm{m}^{2}$ & 01 & 6,3 \\
\hline $260 \mathrm{~g} / \mathrm{m}^{2}$ & 06 & 37,5 \\
\hline $270 \mathrm{~g} / \mathrm{m}^{2}$ & 02 & 12,5 \\
\hline $280 \mathrm{~g} / \mathrm{m}^{2}$ & 05 & 31,3 \\
\hline $300 \mathrm{~g} / \mathrm{m}^{2}$ & 02 & 12,5 \\
\hline
\end{tabular}

Observa-se que todos os hospitais utilizavam o padrão de tecido tipo sarja, cujo ligamento dos fios do urdume transpunham no sentido diagonal os fios da trama. Todos os hospitais seguiam as recomendações de pelo menos 17 fios na trama (fios no sentido transversal) e 14 (87,5\%) possuíam o número abaixo de 40 fios no urdume. Os valores de gramatura foram superiores a $210 \mathrm{~g} / \mathrm{m} 2$ em 15 hospitais (93,7\%).

\section{DISCUSSÃO}

A centralização do CME encontrada na maioria dos hospitais pesquisados é a forma recomendada de organização dessa unidade, pois facilita o controle de todas as etapas e rastreabilidade do processo, além de favorecer a supervisão das atividades, capacitação e educação permanente dos profissionais envolvidos ${ }^{(13)}$.

Entretanto é necessário um enfermeiro coordenando as atividades desenvolvidas pela equipe de enfermagem do CME, visto que essa é uma unidade bastante complexa do hospital, onde estão envolvidos diversos processos de trabalho ${ }^{(14)}$. Vale lembrar que três hospitais não foram incluídos no estudo porque havia um único enfermeiro responsável tecnicamente por toda a instituição. A sobrecarga de atividades e as inúmeras atribuições desempenhadas pelo gerente, em diferentes setores da instituição de saúde, dificultam o planejamento de ações e inviabilizam a prestação de um serviço de qualidade ${ }^{(4,14)}$.

O vapor saturado sob pressão, método de esterilização utilizado em todos os hospitais, é considerado seguro e confiável. Baseia-se em quatro parâmetros: vapor, pressão, temperatura e tempo, e suas vantagens são a disponibilidade do material estéril em curto período de tempo, métodos de controle de qualidade eficazes, possibilidade de validação, ausência de resíduos tóxicos nos materiais e economia(1,3).

A escolha da embalagem compatível e adequada ao método de esterilização é um dos pontos que define a qualidade do processamento, incluindo a manutenção da esterilidade dos produtos para saúde até o seu uso(15). Existem embalagens consideradas ideais ao método de esterilização a vapor saturado sob pressão, cada uma provida de características próprias, que devem ser analisadas frente ao material a ser empacotado, tais como papel grau cirúrgico, não tecido SMS e contêineres rígidos ${ }^{(4-5)}$.

Os hospitais pesquisados utilizavam embalagens apropriadas ao método, à exceção do papel Kraft referido em uma instituição. Essa embalagem, utilizada há muitos anos no país, recentemente foi proibida pela 
ANVISA $^{(2)}$ devido principalmente à presença de amido, corantes e elementos tóxicos que podem ser transferidos durante o processamento, além da irregularidade na gramatura e fragilidade do papel, deixando assim o conteúdo vulnerável(16).

O enfermeiro responsável pelo CME deve acompanhar todas as etapas do processamento, dentre elas a escolha das embalagens de acordo com o processo de esterilização, suas especificações, indicações e cuidados, objetivando oferecer segurança e nível de qualidade elevado(14,17), exigindo embasamento técnicocientífico e efetiva articulação com os setores de provimento de insumos.

Nossos achados mostraram que $81,3 \%$ dos enfermeiros não souberam responder as especificações do tecido em uso no hospital. Evidenciando que estavam alheios a importantes processos que envolviam o seu trabalho e não se apresentavam qualificados tecnicamente para todas as especificidades do gerenciamento da unidade.

Soma-se ainda o fato que metade dos enfermeiros referiu ter poder de decisão no processo de seleção e compra do tecido, masa maioria desconheciaos critérios mínimos regulamentadores, como gramatura e número de fios por $\mathrm{cm}^{2}$, trama e urdume.

Enfatiza-se que o conhecimento e certificação das especificações, no momento de obtenção dos invólucros, fazem parte das atribuições do enfermeiro do $C M E$, que não deve se eximir de sua responsabilidade enquanto coordenador dessa unidade ${ }^{(17)}$ e considerar a viabilidade econômica sem o comprometimento da qualidade.

Considera-se salutar a avaliação e controle dos lotes de tecidos com uso de instrumentos acessórios como lupa e balança, pois, embora se acredite na idoneidade do fornecedor, pode haver lotes com composições diferentes das acordadas no processo de compra, o que refletirá em prejuízos diretos, seja por receber tecidos com qualidade inferior aos pagos, ou por desvio do padrão recomendado à finalidade dos mesmos.

Muitos serviços confeccionavam os campos de tecido usados como invólucro e preparavam os pacotes de acordo com seus próprios critérios. Existem regulamentações para confecção de campos de tecido simples e duplos( ${ }^{(8-9)}$, contudo algumas literaturas demonstram que os campos costurados duplos apresentam desvantagens, visto que as diversas lavagens causam o desprendimento das fibras e seu depósito nas faces internas do campo além de produtos químicos como desagregantes, alvejantes e amaciantes, dificultando a efetividade da limpeza e ocasionando o desprendimento de fibras e resíduos sobre o instrumental, além de comprometer a uniformidade do tecido(4-5). $^{(4)}$

Segurança adicional pode ser fornecida à embalagem de tecido utilizando-se dois campos simples para envolver os produtos para saúde, no momento de preparo do pacote, com a finalidade de manter sua esterilidade e protegê-los de condições adversas de transporte e acondicionamento ${ }^{(4,18)}$.

Destaca-se o fato de todos os hospitais procederem a lavagem do tecido de algodão antes de colocá-lo em uso, conduta necessária para que a goma (amido) seja totalmente retirada, facilitando a passagem do vapor durante a esterilização, além de evitar o superaquecimento e a desidratação das fibras de tecido $^{(19)}$. Entretanto, a literatura não especifica o número ideal de lavagens, enfatizando somente sua necessidade.

A lavagem prévia à confecção seria uma prática importante, pois existe uma margem de encolhimento do tecido $100 \%$ de algodão após umidificado, o que causa sua contratura e encurtamento ${ }^{(4-5,19)}$. Na prática, esta conduta é inviabilizada pela dificuldade de lavar peças inteiras de tecido, uma alternativa para este problema seria testar o encolhimento do tecido antes da confecção, lavando-o por amostragem, e considerar este encolhimento no momento da costura.

Da mesma forma, a lavagem dos campos de algodão entre os processos de esterilização, referida por todas as instituições, é um cuidado recomendado para que se mantenha a umidade das fibras do tecido, prevenindo o superaquecimento do pacote e mantendo as propriedades exigidas para esterilização(20). Alémdisso, muitas vezes os pacotes passam por sucessivos manuseios ou permanecem expostos em ambientes inadequados, agregando sujidade.

Outro aspecto que merece atenção são os critérios de seleção dos campos no momento de preparação dos pacotes. O item integridade inclui ausência de cerzido, remendo, rasgo ou furo, que reduzem a eficiência da barreira microbiana e a qualidade da embalagem. A limpeza prevê a ausência de manchas, resultantes do uso de alvejantes ou amaciantes, resíduos proteicos e sujidade visível ${ }^{(2,5)}$. 
A associação desses dois critérios, indispensáveis a qualquer embalagem de produtos para saúde, foi referida pela maioria dos hospitais pesquisados, que indicaram que os campos de tecido que não mantinham preservadas suas características ideais de uso, eram descartados ou devolvidos à lavanderia para nova lavagem.

Um cuidado importante no uso da embalagem de tecido é o controle do número de vezes que um campo é lavado ou reutilizado, pois devem manter uma barreira de proteção. Porém, com os múltiplos processamentos (lavagem e esterilização) as fibras sofrem modificações que resultam em sua fragilidade e desprendimento, tornando baixa ou nula a eficiência da barreira microbiana, que quando do primeiro uso está em torno de $30 \%$ a $34 \%{ }^{(12,21)}$.

Sendo assim, a inexistência de qualquer tipo de monitoramento da vida útil do tecido de algodão, em praticamente todos os hospitais pesquisados $(87,5 \%)$, traz implicações para a garantia da esterilidade dos produtos para saúde, decorrentes da redução da barreira microbiana do tecido e seu consequente desgaste. Ressalva-se que métodos empíricos de avaliação, de caráter visual e funcional, sem evidências mensuráveis, como foi descrito em um dos hospitais pesquisados, não pode ser considerado um indicador de uso do invólucro.

Apesar de um hospital adotar parâmetros sistemáticos para reutilização dos invólucros de tecido, com troca do enxoval semestralmente (a cada 120 processamentos), um estudo concluiu que os tecidos $100 \%$ algodão destinados à embalagem e padronizados segundo ABNT, mostram-se eficazes como barreira microbiana em até 65 processamentos. A partir daí ocorre alterações das características físicas da embalagem, com redução de gramatura e consequente quebra da barreira microbiana, contaminando assim o instrumental( ${ }^{(110)}$.

A eficácia da barreira microbiana do campo simples $100 \%$ de algodão, conforme padronização da NBR n. 14027/97, destinado à delimitação do campo operatório e preparo da mesa cirúrgica, foi objeto de um estudo que concluiu a quebra da barreira microbiana a partir do sexto processamento e progressiva redução do peso dos campos cirúrgicos quando comparado da primeira à sexta lavagem ${ }^{(120)}$. Portanto, para essa finalidade, a vida útil do campo de tecido é ainda menor.
A utilização contínua do tecido na prática do processamento concorre para o desgaste das fibras têxteis, diminuindo sua propriedade de proteção à medida que é lavado e esterilizado. Isso requer das instituições de saúde protocolos escritos e revisados periodicamente, referentes ao uso desse tipo de invólucro e seu monitoramento sistemático, рага assegurar a qualidade do processamento $(2,15,20)$.

Nesse contexto é possível inferir o importante papel do enfermeiro, enquanto coordenador das atividades desenvolvidas no $\mathrm{CME}$, em instituir estratégias para o controle de qualidade das embalagens de produtos para saúde, por meio de protocolos que permitam quantificar o desgaste e orientar o descarte dos campos de algodão.

Os enfermeiros informaram que as amostras de tecidos novos fornecidos para análise eram 100\% algodão. Empiricamente a textura e visualização (por meio da lupa) do padrão de alinhamento das fibras sugeriram essa constituição. Entretanto a confirmação demandaria uma análise mais criteriosa. Segundo a ABNT o tecido constituído por fibras $100 \%$ de algodão para uso hospitalar, mostra-se resistente e durável(022). Alguns fabricantes de tecidos mistos e sintéticos de menor custo, como o poliéster, afirmam que estes são eficazes e que a barreira microbiana permanece em até 75 processamentos. Todavia não especificam os métodos, a frequência dos testes e se são consideradas as tensões e desgastes oriundos das repetidas lavagens ${ }^{(5)}$.

O tecido colorido para embalar produtos para saúde, como foi observado na maioria dos hospitais que fizeram parte da pesquisa, não é recomendado em algumas literaturas, sendo preconizado para essa finalidade o tecido cru, livre de clareamentos ou tinturas, o que facilita a sua inspeção quanto à limpeza e integridade, além de evitar alteração ou transferência de cor precoce pela exposição a diferentes alvejantes ${ }^{(4-5,19)}$.

O padrão de tecido tipo sarja, usado em todos os hospitais pesquisados, é constituído pelo deslocamento de um fio a cada trama e a repetição do ligamento tem no mínimo três fios, aumentando a qualidade do tecido e potencializando a barreira microbiana ${ }^{(7)}$. Já o padrão tipo tela é um ligamento mais simples, onde os fios da trama e urdume estão entrelaçados de forma quadriculada em ângulos de $90^{\circ}$, ora o fio do urdume passa por cima, ora por baixo do fio da trama, fazendo com que normalmente o espaçamento entre os fios seja maior ${ }^{(7)}$. 
Recomenda-se, para confecção do campo de algodão, o uso do tecido T1, Sarja (2x1), em que há dois fios no urdume para cada fio entrelaçado na trama, ou do tecido T2, Sarja $(3 \times 1)$, com três fios no urdume para cada fio de trama ${ }^{(22)}$, sendo esse último encontrado em $68,7 \%$ dos hospitais que fizeram parte deste estudo.

A maioria das amostras de tecido analisadas possuía urdume abaixo de 40 fios, contudo seguiam as normas vigentes quanto às outras especificações como: padrão, $\mathrm{n}^{\circ}$ de fios por $\mathrm{cm}^{2}$ e trama $\left.{ }^{(8-9} 0\right)$. Destaca-se que o número de fios é um dos pontos que determinam a eficácia da barreira microbiana do tecido de algodão para uso hospitalar, sua resistência a rasgos e perfurações e capacidade de proteger o conteúdo do pacote ${ }^{(22)}$.

Apenas duas instituições apresentaram amostras de tecido com número de fios superior a 56 por $\mathrm{cm}^{2}$. Em décadas anteriores acreditava-se que o aumento do número de fios do tecido e consequente diminuição do espaço entre eles potencializava a barreira microbiana. Posteriormente, foi identificado que a grande quantidade de fios dificultava a passagem de vapor e comprometia a esterilização(4-5).

Apesar de a maioria dos hospitais exceder a variação especificada pela $A B N T$, de $5 \%$ abaixo ou acima no valor de gramatura de $210 \mathrm{~g} / \mathrm{m}^{2(8-9)}$, não foram encontrados estudos que relacionassem o aumento da gramatura do tecido com prejuízos na esterilização e na manutenção da esterilidade do produto até o uso0.

\section{CONCLUSÕES}

Os 16 hospitais de médio e grande porte, participantes desse estudo utilizam o tecido de algodão como embalagem para produtos para saúde processáveis.

Apesar do enfermeiro do CME e/ou Centro Cirúrgico ser, na metade dos hospitais $(50,0 \%)$, o responsável pela aquisição do tecido usado como invólucro de produtos para saúde, a maioria, 13 (81,3\%), não sabia responder quanto às especificações do tecido em uso na instituição
( ${ }^{\circ}$ de fios por $\mathrm{cm}^{2}$, padrão e gramatura) e apenas três enfermeiros $(18,7 \%)$ citaram a associação entre os itens gramatura, $\mathrm{n}^{\circ}$ de fios por $\mathrm{cm}^{2}$, cor e preço do tecido como características priorizadas na aquisição.

Na maioria dos hospitais os campos de tecido eram confeccionados simples e utilizava-se um campo simples e um duplo para envolver os produtos para saúde, no momento de seu empacotamento.

A análise das amostras novas de tecido de algodão, utilizadas pelos hospitais como embalagem, mostrou que a maioria seguia as especificações da Associação Brasileira de Normas técnicas. Contudo, na maior parte dos hospitais não era estabelecido qualquer tipo de monitoramento da vida útil dessa embalagem, sendo utilizada até a exaustão e desprezada somente quando havia indícios visuais de falta de integridade (rasgos ou furos), comprometendo a segurança do produto. Apenas um hospital relatou algum controle no reuso dos invólucros de tecido de algodão.

As recomendações e normas existentes, sobre a seleção e uso do tecido de algodão para embalar produtos para saúde, fornecem subsídios para análise e discussão quanto ao modo de atuação mais seguro dos profissionais e instituições de saúde onde se utiliza esse invólucro. Рara isso é necessário o envolvimento da equipe de diversos setores, como CME, Centro Cirúrgico, Serviço de Controle de Infecção, Compras e Lavanderia, para que possam implantar medidas de controle e avaliação das características, desempenho e seleção da embalagem de tecido.

O enfermeiro tem nesse processo um papel fundamental, enquanto coordenador do CME, devendo assumir sua função com competência técnica e participar efetivamente do processo de compra, avaliação e controle do uso de embalagens de tecido, com vistas a garantir maior segurança aos usuários que utilizam produtos para saúde processados no vapor saturado sob pressão e embalados com esse invólucro.

http://bvsms.saude.gov.br/bvs/saudelegis/anvisa/2012/rdc0015 15 03_2012.pdf.

3. Padovese MC, Quelhas MC, Nakamura MHY. Métodos físicos de esterilização. In: Padoveze MC, Graziano KU. Limpeza, desinfecção e esterilização de artigos em serviços de saúde. São Paulo: APECIH; 2010. p. 108-25.

4. Sociedade Вrasileira de Enfermeiros de Centro Cirúrgico,

Recuperação Anestésica e Centro de Material e Esterilização. Práticas recomendadas. São Paulo: SOBECC; 2009.

\section{REFERÊNCIAS}

1. Tipple AFV, Pires FV, Guadaguanin SVT, Melo DS. O

monitoramento de processos físicos de esterilização em hospitais do interior do estado de Goiás. Rev Esc Enferm
[cited 2012 dec 31]:45(3):751-7. Available from: http://dx.doi.org/10.1590/S0080-62342011000300029. 2. Resolução da Diretoria Colegiada/ANVISA - RDC No 15 , de 15 de março de 2012 (BR). Dispõe sobre requisitos de boas práticas para o processamento de produtos para saúde e dá outras providências [cited $2012 \mathrm{dec}$ 31]. Available from: 
5. Pereira MCO. Preparo, embalagem, transporte e armazenagem. In: Padoveze MC, Graziano KU. Limpeza, desinfecção e esterilização de artigos em serviços de saúde. São Paulo: APECIH; 2010. p. 83-107. 6. Alarcon CDP, Graziano KU, Hadi MA, Camargo TC. Contêineres rígidos: avaliação do usuário. Rev. SOBECC [Internet]. 2005 [cited 2012 dec 31];10(2):33-9. Available from:

http://novo.sobecc.org.br/artigo/artigo_102.pdf.

7. Associação Brasileira de Normas Técnicas. NBR 12546. Materiais têxteis - ligamentos fundamentais de tecidos planos - Terminologia. Rio de Janeiro: ABNT; 1991.

8. Associação Brasileira de Normas Técnicas. NBR 14027. Roupa hospitalar - confecção de campo simples. Rio de Janeiro (Brasil): ABNT; 1997.

9. Associação Brasileira de Normas Técnicas. NBR 14028. Roupa hospitalar - confecção de campo duplo. Rio de Janeiro (Brasil): ABNT; 1997.

10. AORN. Association of Operating Room Nurses. Recommended Practices for selection and use of packaging systems. In: Standards Recommended Practices, and Guidelines. AORN Inc, Denver, 2004. Section 3, p. 329-34.

11. Rodrigues E. Reutilização de campos duplos de tecido de algodão padronizados pela ABNT utilizados para artigos médicohospitalares na esterilização por calor úmido [thesis]. São Paulo: Escola de Enfermagem da Universidade de São Paulo; 2000. 12. Burgatti JC, Possari JF, Moderno AMB. Avaliação da barreira microbiana do campo cirúrgico de algodão. Rev. SOBECC [Internet]. 2004 [cited 2012 dec 31];9(1):24-32. Available from:

http://novo.sobecc.org.br/artigo/artigo 83.pdf.

13. Guadagnin SVT, Tipple AFV, Souza ACS. Avaliação arquitetônica dos centros de material e esterilização de hospitais do interior do estado de Goiás. Rev Eletr Enf [Internet]. 2007 [cited 2012 dec 31]; 9(3):656-73. Available from:

http://www.fen.ufg.br/revista/v9/n3/v9n3a07.htm.

14. Resolução No 424/2012 - COFEN (BR). Normatiza as atribuições dos profissionais de Enfermagem em Centro de Material e

Esterilização e em empresas processadoras de produtos para saúde. [cited 2012 dec 31]. Available from:

http://site.portalcofen.gov.br/node/8990.

15.Brito MFP, Galvão CM, Françolin L, Rotta CSG. Validação do processo de esterilização de artigos médico- hospitalares segundo diferentes embalagens. Rev Bras Enferm [Internet]. 2002 [cited 2012 dec 31];55(4):414-9. Available from: http://bvsms.saude.gov.br/bvs/is digital/is 0303/pdfs/IS23(3)067.p df.

16. Costa EAM. Estudo de custo benefício de embalagens para esterilização. Rev. SOBECC [Internet]. 2004 [cited 2012 dec 31];9(4):38-43. Available from: http://novo.sobecc.org.br/artigo/artigo 96.pdf.

17. Santos IBC, Oliveira TL, Nogueira MJF. A embalagem рага esterilização sob a ótica assistencial do enfermeiro. Rev. SOBECC [Internet]. 2002 [cited $2012 \mathrm{dec} 31$ ]; 7(1):17-20. Available from: http://novo.sobecc.org.br/artigo/artigo_67.pdf.

18. Associação Brasileira de Normas Técnicas. NBR 13546. Roupas Hospitalares- Terminologia. Rio de Janeiro (Brasil): ABNT; 1996.

19. Moura MLPA. Requisitos mínimos para realização dos processos de esterilização. In: Moura MLPA. Enfermagem em Centro de Material e Esterilização. São Paulo: SENAC; 2007. p. 13-4.

20. Bruna CQM. Preparo e embalagens dos materiais para a esterilização. In: Graziano KU, Silva A, Psaltikidis EM, organizadores. Enfermagem em centro de material e esterilização. São Paulo: Manole; 2011. p. 92-108.

21. Mizusaki T, Possari JF, Araújo CC. Avaliação dos custos referentes ao reprocessamento dos campos cirúrgicos simples feitos de $100 \%$ de algodão e aos campos descartáveis (não tecido). Rev. SOBECC [Internet]. 2004 [cited 2012 dec 31];9(3):27-36. Available from: http://novo.sobecc.org.br/artigo/artigo 95.pdf. 22. Associação Brasileira de Normas Técnicas. NBR 13917. Material têxtil - tecido plano de $100 \%$ algodão para roupas profissionais e uniformes. Rio de Janeiro (Brasil): ABNT; 1997.

Artigo recebido em 21/12/2011.

Aprovado para publicação em 11/06/2012.

Artigo publicado em 31/12/2012. 